\title{
Characteristics Of Poultry Litter Biodiesel With Magnalium And Cobalt Oxide As A Additives
}

\author{
P.Karthikeyan, S.Yuvaraja, R.Kumarasubramanian, G. Sanjeeth, K. Sai Karthik
}

\begin{abstract}
The importance of bio diesel in CI engine has substantiated, the recent research has been motivated on the use of different Nano materials as additives in diesel engines. The present investigation is to study the performance and emission characteristics of a single cylinder direct injection CI engine using transesterified Poultry litter(PL) biodiesel blend with and without Cobalt oxide and Magnalium nanoparticles as additives. This biodiesel blends with diesel, and biodiesel-diesel-nanoparticles with each and both the nano additives are tested in CI engine with constant speed of 1600 rpm with variation loads low to high. The performance parameters like Brake power, Brake specific energy consumption, Brake specific fuel consumption and efficiency of both Mechanical and volumetric are measured by VCR engine setup, emission characteristics like $\mathrm{NO}_{2}, \mathrm{CO}, \mathrm{UBHC}$ are measured by GAS ANALYSER these results are compared with pure diesel or neat diesel. The $\mathrm{NO}$ emissions gradually reduced for $\mathrm{B2OCo}_{3} \mathrm{O}_{4}$ Al-mg test fuel with percentage of $7.5 \%$ to the diesel and $\mathrm{B} 20$ to $11 \%$ for the diesel. Under maximum load of $10 \%$, observed that there is improvement in Brake thermal efficiency for B20Al-Mg $30 \mathrm{ppm} \mathrm{Co}_{3} \mathrm{O}_{4} 30 \mathrm{ppm}$ and followed by $9 \%$ improvement in Brake thermal efficiency for $\mathrm{B2O}^{\mathrm{Co}} \mathrm{O}_{3} \mathrm{O}_{4} 30 \mathrm{ppm}$ and followed by $4 \%$ increase in biodiesel test fuel, compared to diesel.
\end{abstract}

\section{INTRODUCTION}

In the current situation, a diesel engine plays a significant role among all the fossil fuels because of its higher brake thermal efficiency but it becomes the main cause of air pollution due to its exhaust gas emissions and moreover the sources of fossil fuels are decreasing gradually. Therefore, many of the scientists and researchers consider the biodiesel as alternative fuel for future developing demand [1] Biodiesel is improved for using in diesel engines due its considerable properties as a diesel fuel because they are renewable as well as environmentally friendly. It can be made from vegetable oil, animal oils and fish oils such as pongamia, jatropha, mustard, rapeseed, soybean, yellow oil, chicken oil and fish oil [2]. Many researchers considered the $\mathrm{CI}$ engine using different biodiesels and its blends to improve the performance and reducing the emissions by adopting engine geometry modification and fuel property variation. Based on the works and the experimental studies, Nabi et al. [3] enhanced the diesel engine using cotton seed as a biodiesel mixtures of B10, B20 \& B30. They found that there

Revised Manuscript Received on December 22, 2018.

P.Karthikeyan, Assistant Professor, School of Mechanical Engineering, Sathyabama Institute of Science \& Technology, Chennai, India.

S.Yuvaraja, Assistant Professor, School of Mechanical Engineering, Sathyabama Institute of Science \& Technology, Chennai, India. Engineering, Sathyabama Institute of Science \& Technology, Chennai, India. Sathyabama Institute of Science \& Technology, Chennai, India.

K. Sai Karthik, Undergraduate Scholar, School of Mechanical Engineering, Sathyabama Institute of Science \& Technology, Chennai, India.
R.Kumarasubramanian, Assistant Professor, School of Mechanical

G. Sanjeeth, Undergraduate Scholar, School of Mechanical Engineering,

is decrease in formation of pollution because of improved combustion rate due to excess oxygen content and decreased brake thermal efficiency due to its high viscosity and density. Gopal et al. [4], considered Pongamia biodiesel and its combination to study the performance and emission features on CI engine. They conclude that there is increase in specific fuel consumption for biodiesel blends due to reduced heating value of Pungamia biodiesel. Also, they found that there is a considerable reduction in emissions of carbon monoxide, hydrocarbon and smoke for biodiesel blends and emission of $\mathrm{NO}_{\mathrm{X}}$ was little bit higher than that of diesel characteristics. Further the biodiesel fueled engines increases the specific fuel consumption and reduces the thermal effectiveness and torque. $\mathrm{No}_{\mathrm{x}}$ emissions are increased slightly and $\mathrm{CO}, \mathrm{HC}$ and smoke emissions are reduced significantly [5-7].

Based on the above literature review extended the study of different biodiesel with different blends, and a group of Researchers tried to apply Nano technology in the area of engines to improve its working characteristics. Nano additives are used to advance the standards of combustion, performance and emission features of the engine. Nano additives are selected based on the weakness of the fuel characteristics and properties like combustion, ignition delay, cetane number, flash point, calorific value, density and viscosity. To improve the excellence of the petroleum the metal based, oxygenated, improver cetane number and antioxidant nano additives are used.

Metal based additives such as $\mathrm{CuCl}_{2}, \mathrm{FeCl}_{3}, \mathrm{CuO}$-nano structured, $\mathrm{CoCl}_{2}$ and $\mathrm{CuSO}_{4}$ are used to reduce the fuel intake and hydrocarbon emission, also to promote complete combustion. The oxygenated additives are used to increase the combustion procedure and octane rate. It is necessary to maintain the cetane number for biodiesel and diesel, by combination oxygenated additives it will increase the quantity of cetane value. Alcohols, ether and ester are used as oxygenated additives. To minimize the ignition delay, cetane number activists are used. Complete combustion of the fuel in IC engine will reduce the noise and emissions, minimizing the ignition delay period lead to complete combustion of the fuel. Aldehydes, nitrates, tetra-azoles, and alkyl nitrates are commercially used as a cetane number improvers [8,9]. To increase the stabilizing potential of biodiesel mix antioxident additives are used and also it's slow down the slush deposit. Generally butylated hydroxyl anisole, butylated hydroxyl toluene, pyrogallol, diphenylamine, tert-butylhydroxyquinone and propyl-gallate are used as antioxident[10].

Selvan et al. studied the properties of Cerium oxide blended diesel-biodiesel ethanol blends in CI engine, they noticed that the reduction in ignition delay period and small 
improvement in break thermal efficiency. Engine operates on lean mixture than neat diesel and significant reduction in exhaust emission [11].

Basha and Anand examined the water-diesel emulsion fueled CI engine with alumina added nano additives, they observed that low cylinder peak pressure, lesser heat release rate and reduced $\mathrm{NO}_{\mathrm{X}}$ emission [12].Fangsuwannarak et al selected $\mathrm{TiO}_{2}$ added palm oil biodiesel to check the performance of diesel engine, they observed that the decreased specific fuel consumption and improved cetane number. Also, appreciable reduction in $\mathrm{CO}_{2}, \mathrm{CO}$ and $\mathrm{NO}_{\mathrm{X}}$ emissions [13].

Sajith et al. investigated the diesel engine by using $\mathrm{CeO}_{2}$ nano additive with the jatropha biodiesel fuel, and found a considerable reduction of destructive emissions, and improved brake thermal efficiency owed to their enhanced catalytic activity [14]. Ors I et al studied $\mathrm{TiO}_{2}$ mixed waste cooking oil biodiesel to inspect their possessions on diesel engines. The addition of $\mathrm{TiO}_{2}$ improved the torque power and power and reduced the brake specific fuel consumption compared to blends without additive.

The current study is to consider the possibility of consuming PL oil biodiesel obtained from wastes of poultry industries as an alternative fuel for diesel. The energetic properties of PL, its sustainable use as energy can be obtained through thermochemical processes. As a result, there is the potential for generating heat and flue gas with low emission of pollutants [15]. Also the performance and emission characteristics of PL oil biodiesel are compared by adding cobalt oxide and maganaluim as a Nano additive.

\section{MATERIALS AND METHODS}

\section{Poultry Litter Oil Preparation}

The non-eatable PL(Poultry litter) fresh oil is recycled to produce the biodiesel fuel using a Laboratory Scale Biodiesel Reactor. The reactor consists of 3 necked $1200 \mathrm{~mL}$ flat bottom flask attached with beakers, mechanical stirrer, reflux condenser and thermometer to maintain the constant speed and temperature. The properties of both biodiesel fuel and the usual PLO are listed.

Table 1 Properties of Poultry litter oil

\begin{tabular}{|c|l|l|}
\hline S.No & \multicolumn{1}{|c|}{ Properties } & \multicolumn{1}{|c|}{ Results } \\
\hline 1 & Density & $0.737 \mathrm{~g} / \mathrm{cc}$ \\
\hline 2 & Kinematic Viscosity @ $40^{\circ} \mathrm{C}$ & $5.48 \mathrm{cSt}$ \\
\hline 3 & Flash point by PMCC method & $158^{\circ} \mathrm{C}$ \\
\hline 4 & Fire Point by PMCC method & $178^{\circ} \mathrm{C}$ \\
\hline 5 & Calorific Value & $29000 \mathrm{KJ} / \mathrm{Kg}$ \\
\hline
\end{tabular}

\section{Transesterification}

A hot plate with magnetic stirrer in the flask is used for heating the mixture. The mixture is disturbed at the constant speed the temperature series of $50-60^{\circ} \mathrm{C}$ is maintained for complete test run.

The parameters such as alcohol to molar ratio of oil, reaction temperature, amount of catalyst, and extent will affect the

transesterification process and these are analysed by conducting some experiments.

\section{Acid catalysed Pre-treatment reaction}

The sulphuric acid is an efficient catalyst for esterification process. Therefore, sulphuric acid was selected as the catalyst. In demand to optimize $600 \mathrm{ml}$ of methanol and $0.6 \%$ of sulphuric acid is added to the one liter of the PL oil. Then the blend is transferred into the flask and temperature is increased to about $60^{\circ} \mathrm{C}$. Reheating and stirring is continued for 30-60 min at room temperature. After that the additional alcohol is seperated by pouring the mixture into the separating funnel. The bottom layer is utilized for base esterification process and the top layer contains the removable alcohol, with sulphuric acid and layers are removed.

\section{Base Catalysed Transesterification}

After the acid transesterification process the allowed fatty acids in the PL oil was reduced to less than one percent. Alkaline catalysed esterification process is recycled to transfer the pre-treated oil into biodiesel. Transesterification involves stripping the glycerine from fatty acids and producing Fatty acid methyl ester. Sodium hydroxide was taken as a catalyst and methanol is to replace the glycerine. The mixture is first warmed to the essential reaction temperature of $60 \pm 5^{\circ} \mathrm{C}$ in the flask. Meanwhile, methanol molar ratio of $6: 1$ is taken in a round bottom flask $0.5 \%$ of $\mathrm{NaOH}$ catalyst is dissolved and the mixture is heated to $60^{\circ} \mathrm{C}$ for 50 to $60 \mathrm{~min}$. After that the blend is permitted to separate into two deposits. The upper deposit contains esters and lower deposit contains dusts and glycerol, is drawn off. Then the hot purified water discharged over the surface of the ester and forms the yellow layer (bio diesel) is detached.

\section{Blending the Biodiesel}

The PL oil prepared through the transestrification process further the blending process is done. B20 is equipped by mixing $20 \%$ by size of biodiesel with $80 \%$ of diesel, B20 $\mathrm{Co}_{3} \mathrm{O}_{4} 30(\mathrm{ppm})$ is prepared by $30 \mathrm{mg}$ of Cobalt oxide nano particle of B20 biodiesel blend, B20 Al-Mg 30(ppm) is equipped by $30 \mathrm{mg}$ of Magnalium nano particle of B20 biodiesel blend. The nanoparticles are added to the blends by ultrasonication method by Water bath sonicator with frequency of 20 hertz for $30 \mathrm{~min}$ for each blend. The nanoparticles are biased rendering to the predefined segment of $30 \mathrm{mg} / \mathrm{l}$ and varied with B20 biodiesel in an ultrasonicator. To stabilize the nano particles, Cetyl Trimethyl Ammonium Bromide surfactants are added to reduce the surface tension among fuel and nanoparticles.

\section{Engine test}

A single-cylinder has 4-stroke, direct injection VCR diesel engine with a maximum rated output of $3.50 \mathrm{~kW}$ at $1500 \mathrm{rpm}$ was utilized to obtain the set of experimental data required .The engine has a CR of 18. The engine has a swept volume of 661.45 (cc), bore diameter of the engine is $87.50 \mathrm{~mm}$ and stroke length of $110.00 \mathrm{~mm}$. Injection pressure is $210 \mathrm{bar}$ maintained constantly throughout the process.

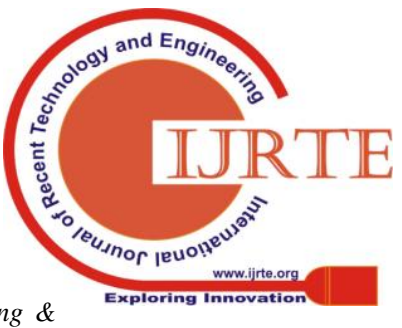




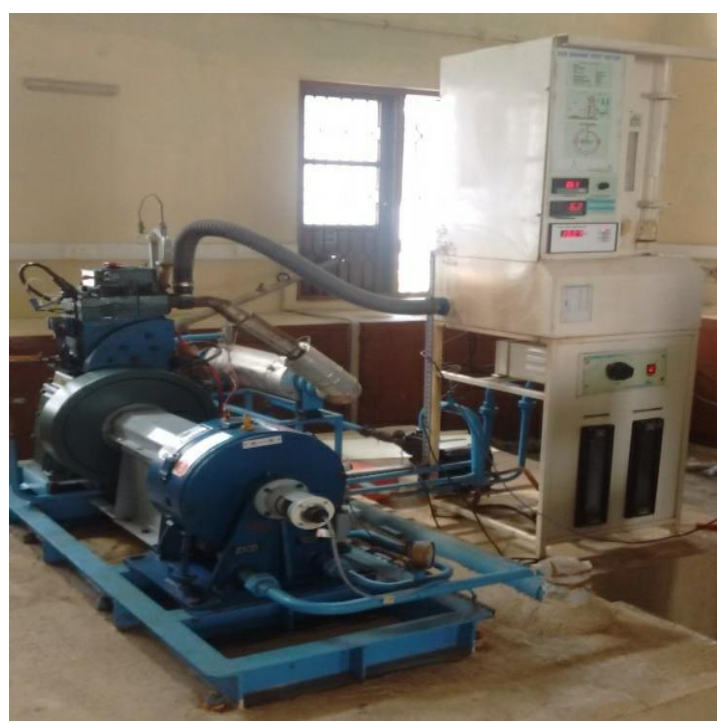

Figure 1 Experimental setup

Table 2 Specifications of Test Engine

\begin{tabular}{|c|c|}
\hline Engine model & VCR ENGINE \\
\hline Power & $3.50 \mathrm{Kw}$ \\
\hline Speed & $1500 \mathrm{rpm}$ \\
\hline Number of cylinders & Single Cylinder \\
\hline Number of stroke & Water Cooled \\
\hline Cooling system & $87.50(\mathrm{~mm})$ \\
\hline Cylinder Bore & $110.00(\mathrm{~mm})$ \\
\hline Stroke Length & $234.00(\mathrm{~mm})$ \\
\hline Connecting Rod length & 18 \\
\hline Compression Ratio & $661.45(\mathrm{cc})$ \\
\hline Swept volume & $210 \mathrm{Bar}$ \\
\hline Injection pressure & \\
\hline
\end{tabular}

\section{RESULT AND DISCUSSION}

\section{PERFORMANCE}

\section{Effect of brake thermal efficiency against Brake Power}

Brake Thermal Efficiency is derived from the brake power of the heat engine to the heat input from the burned fuel. It is used to calculate the change of heat into mechanical energy.

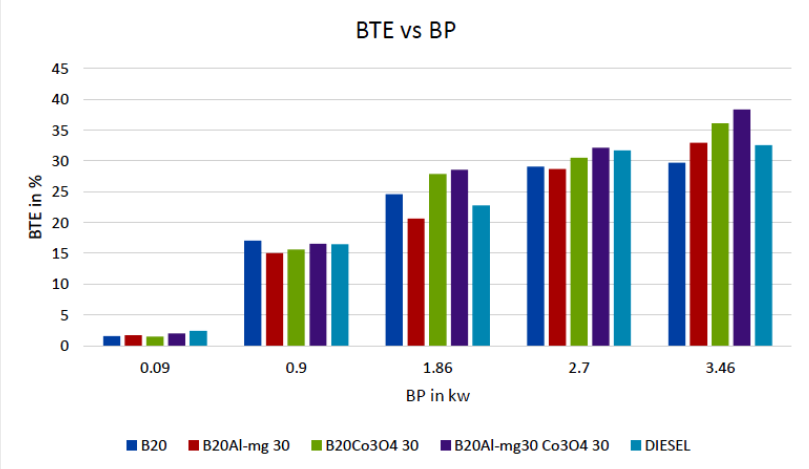

Figure 2 Variation of BTE with BP

Above graph shows the performance of diesel engine with different fuels blends. The observed brake thermal efficiency for $\mathrm{B} 100$ or $\mathrm{D} 100, \mathrm{~B} 20, \mathrm{~B} 20 \mathrm{Co} 3 \mathrm{O} 4$ 30ppm, B20 Al-Mg 30ppm, B20Al-Mg 30ppm Co3O4 30ppm is compared and nanoparticles dispersed gives greater Brake Thermal efficiency, since the atomization and fast vaporization of Nanoparticles spreaded fuels, resulting in well air fuel mixing and permits additional surface area of fuel to react 25 oxygen molecule. Though the cobalt oxide is rich in oxygen content and magnesium in magnalium alters the combustion.

\section{Effect of Specific Fuel Consumption(SFC)}

Increase in SFC will lessen the efficiency of the engine. If an engine has less SFC it means it is high efficient.

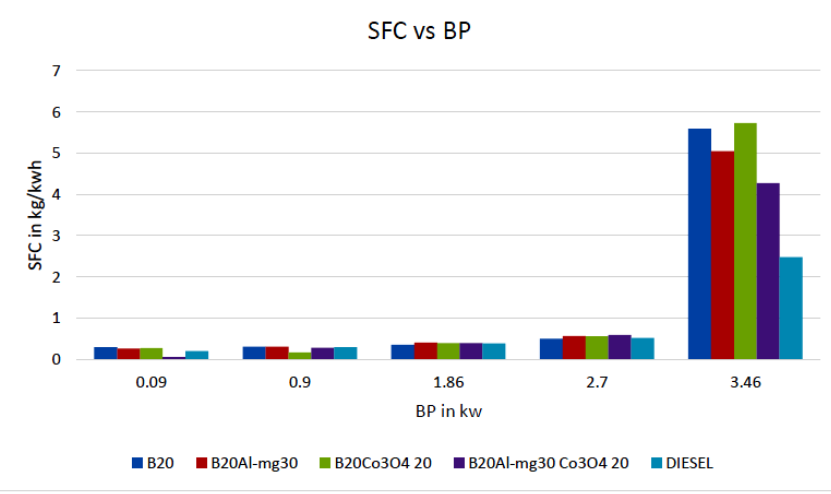

Figure 3 Performance graph against SFC and BP

The graph shows Fig. 3 comparison between the SFC and brake power. At lower load SFC of B20Al-mg $\mathrm{Co}_{3} \mathrm{O}_{4}$ is less when compared with other blends. Diesel and bio diesel blends are not having much variance in fuel consumption. At higher load B20Al-mg is consuming less fuel then $\mathrm{Co}_{3} \mathrm{O}_{4}$ due to rich air mixture existing in the combustion chamber.

\section{Effect of Mechanical Efficiency}

Mechanical efficiency deals the effectiveness of the engine in trans-forming the heat energy into an output force and movement. The mechanical efficiency of bio diesel with both nanoparticles gives higher result comparatively to diesel, the efficiency increased by $9 \%$ bio diesel and $11 \%$ by diesel.

Usually the test fuel with high brake thermal efficiency leads to high mechanical efficiency as listed above the bio diesel with nanoparticles gives higher efficiency.

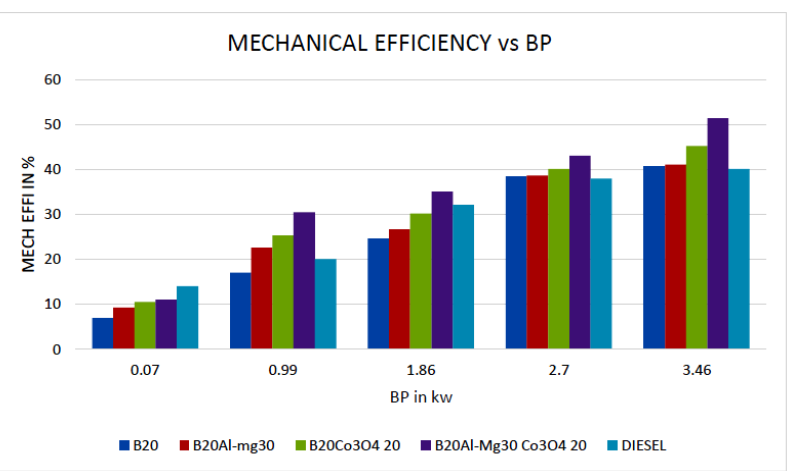

Figure 4 Performance graph against Mech. Eff. and BP

Published By:

Blue Eyes Intelligence Engineering \&

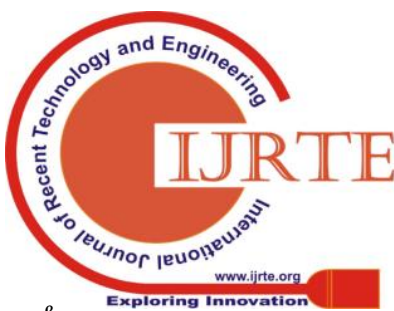

Sciences Publication 


\section{EMISSIONS}

\section{Effect of Carbon Monoxide emission}

The Carbon monoxide (CO) is a colourless, odourless, and tasteless gas that is somewhat less thick than air. It is deadly to haemoglobin animals (including humans) when met with concentrations greater than $35 \mathrm{ppm}$, although it is also shaped in usual animal metabolism in lower amounts, and is supposed to have some usual biological meanings.

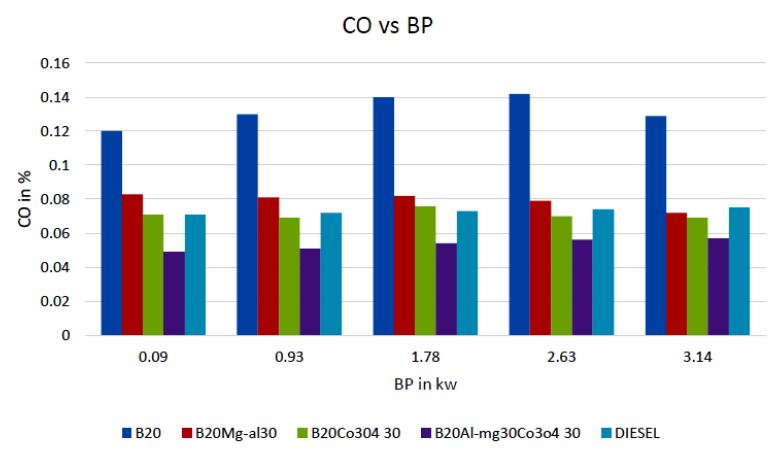

Figure 5 Emissions graph $\mathrm{CO}$ vs $\mathrm{BP}$

The CO emissions of diesel engine with the pure diesel and bio diesel with both nanoparticles and each nanoparticles is compared above by graph fig. 5. The $\mathrm{CO}$ emissions for B20 is advanced for all the loads due to less atomization. The $\mathrm{CO}$ emissions are condensed nanoparticles blend when compared with the pure diesel and bio diesel. The emission of carbon monoxide is reduced by $42 \%$ by using biodiesel with both cobalt oxide and magnalium nanoparticles to the bio diesel. The emissions of $\mathrm{CO}$ is reduced by $24 \%$ by biodiesel with nanoparticles to the pure diesel. Due to inherent oxygen content the $\mathrm{CO}$ is converted to $\mathrm{CO}_{2}$. And the fine atomization and fast vaporization of fuel.

\section{Effect of Hydrocarbon Emission}

High Hydrocarbons are almost always a sign of poor fuel ignition and due to incomplete combustion and fast vaporization of fuel. Hydrocarbons are a major contributor to smog Methane is not straightaway poisonous, but is more problematic to breakdown in fuel vent lines and a charcoal canister is meant to accumulate and hold fuel vapours and direct them both back to the fuel tank or, afterwards the engine is started and warmed up, into the air intake to be burned in the engine

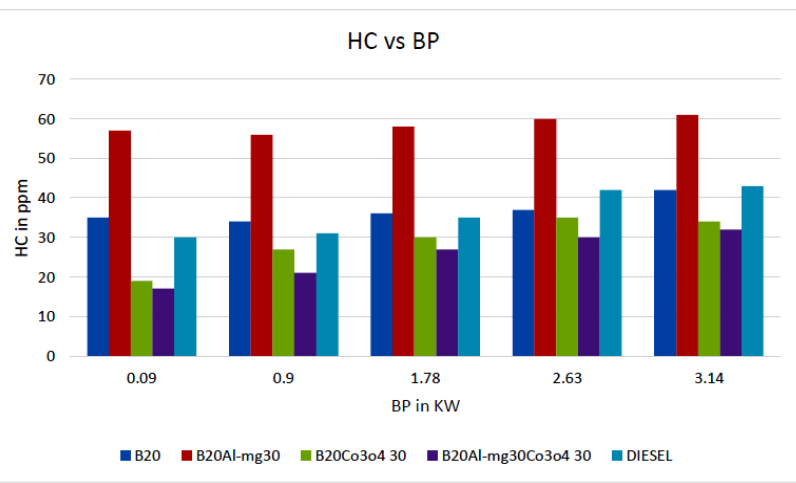

Figure 6 Emissions graph HC vs BP

The figure 6 Illustrate the emissions analysis of $\mathrm{HC}$ of biodiesel and biodiesel with cobalt oxide and magnesium alumina and pure diesel. The pure diesel and biodiesel alone with alumina give higher emissions matched to other blends. The $\mathrm{HC}$ emissions of $\mathrm{B} 20 \mathrm{Co}_{3} \mathrm{O}_{4}$ and $\mathrm{B} 20 \mathrm{Co}_{3} \mathrm{O}_{4} \mathrm{Al}$-mg gives lesser emissions matched to pure diesel. The $\mathrm{HC}$ emissions B20 $\mathrm{Co}_{3} \mathrm{O}_{4} \mathrm{Al}-\mathrm{mg}$ is reduced by $50 \%$ to biodiesel and reduced by $30 \%$ to the pure diesel. Same as $\mathrm{CO}$ due to oxygen content the $\mathrm{HC}$ converts into $\mathrm{H}_{2} \mathrm{O}$. Due to fine mixing of air and fuel the combustion will be rich and reduce the UBHC.

\section{Effect of NOx Emission}

NOx gases are usually produced from the reaction among nitrogen and oxygen during combustion of fuels, such as HC in air; especially at high temperature, such as occur in car engine, some studies prove that they reduce harmful tailpipe emissions such as $\mathrm{CO} \& \mathrm{HC}$ emissions but sometimes decrease NOx. and sometimes increase the emissions. 20\% biodiesel in USEPA permitted diesel fuel have no significant effect on NOx. These emissions caused by high combustion temperature and its reductions give better efficiency.

The figure 7 illustrate the emissions analysis of NOx of biodiesel and biodiesel with cobalt oxide and magnesium alumina and clean diesel. The clean diesel and biodiesel alone with alumina give higher emissions related to other blends. The HC emissions of B20 Co3O4 and B20Co3O4 Al-mg gives lesser emissions compared to pure diesel at lower BP and have no major change at higher BP or load. The NOx emissions biodiesel is reduced by $11 \%$ to $\mathrm{B} 20 \mathrm{Co} 3 \mathrm{O} 4$ $\mathrm{Al}-\mathrm{mg}$ and reduced by $7.5 \%$ to the clean diesel

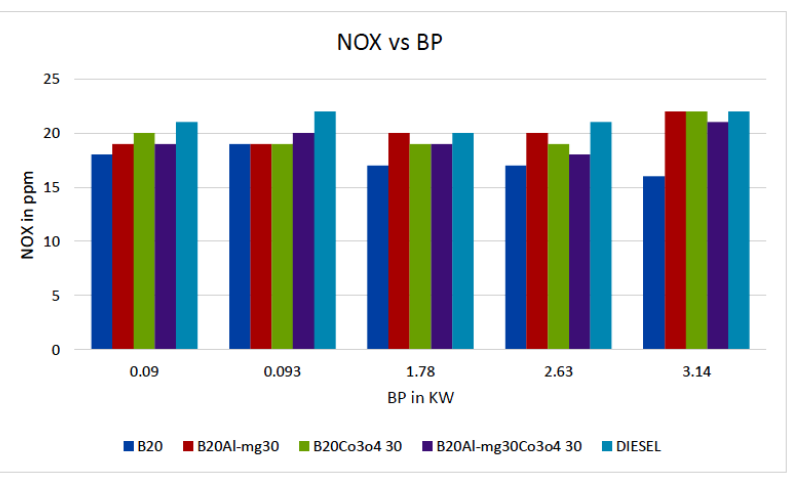

Figure 7 Emissions Graph NOx vs BP

Overall emissions are condensed by the biodiesel and with biodiesel of nanoparticles combined when compared to clean diesel. Normally the biodiesel contains the dual bond molecules it leads to greater adiabatic flame temperature than the diesel fuel, which leads to growth in NO emissions. Due to ability of nanoparticles scavenge the nitric acid to $\mathrm{N}_{2}$ and lower the level of $\mathrm{NO}$ values. $\mathrm{NO}_{\mathrm{X}}$ emission of B20 $\mathrm{Co}_{3} \mathrm{O}_{4} \mathrm{Al}-\mathrm{mg}$ looks to decrease slightly as related to that of diesel, as the catalytic behaviour of nanoparticles will head the reaction to be finalized products with the minimum thermal break down of the hydrocarbon mixtures.

\section{Conclusions}

The performance and emissions characteristics of nanoparticles spreaded test fuels are examined in a single-cylinder has 4-stroke diesel engine. The engine test conducted with blends of $\mathrm{B} 20$ $\mathrm{PL}$ oil and $\mathrm{B} 20 \quad \mathrm{Co}_{3} \mathrm{O}_{4}$ 30ppm, B20 Al-Mg 30ppm, B20Al-Mg $30 \mathrm{ppm} \quad \mathrm{Co}_{3} \mathrm{O}_{4}$ $30 \mathrm{ppm}$ as additives for zero 
load to full form and the equivalent performance and emissions characteristics were studied. As results and references states strongly that PL oil combined with diesel is suitable for replacement of clean diesel as fuel.

The B20 PL oil biodiesel with and without nanoparticles as additive indicates increased in Brake thermal efficiency with respect to diesel at maximum load. The significant increase in brake thermal efficiency is observed for nanoparticles spreaded as additives in test fuels related to those of D100. Under extreme load of $10 \%$ improvement in BTE for B20Al-Mg 30ppm $\mathrm{Co}_{3} \mathrm{O}_{4} 30 \mathrm{ppm}$ and followed by $9.5 \%$ improvement in $\mathrm{BTE}$ for $\mathrm{B} 20 \mathrm{Co}_{3} \mathrm{O}_{4} 30 \mathrm{ppm}$ and followed by $4 \%$ increase in biodiesel test fuel, related to diesel. The additions of nanoparticles in biodiesel decreases the ignition delay and accelerates earlier initiation of combustion which results in lower heat release rate and cylinder pressure at full load condition. For B20 the emissions of $\mathrm{HC}$ and $\mathrm{CO}$ are slightly high at low load and reduce with the increase in load comparatively to pure diesel. The use of nanoparticles alters the performance of diesel engine in mechanically but also reduces emission level of pollutants in due to catalytic effect on fuel combustion process in comparison effect of biodiesel - diesel blends. The NO emissions gradually reduced for B20 $\mathrm{Co}_{3} \mathrm{O}_{4} \mathrm{Al}-\mathrm{mg}$ test fuel with percentage of $7.5 \%$ to the diesel and B20 to $11 \%$ for the diesel.

Overall, the performance and emissions characteristics of a diesel engine are improved by nanoparticles cobalt oxide and magnesium alumina as additive in bio diesel and diesel blend. Using renewable and eco-friendly fuels like PL oil bio diesel with or nanoparticles a important percentage of limited diesel thus can be eliminated. Thus this strong factor shows the fact PL oil blended with diesel can be a hopeful fuel for diesel engines in future as they have good efficiency and reduced emissions.

\section{REFERENCES}

[1] R.D. Misra, Straight vegetable oils usage in a compression ignition engine, Renew. Sustain. Energy Rev. 13 (2010).

[2] Agarwal AK, Gupta JG, Dhar A. Potential and challenges for large-scale application of biodiesel in automotive sector. Prog Energy Combust Sci 2017;61:113-49.

[3] M. N. Nabi, M. M. Rahman, M. S. Akhter, Biodiesel from cotton seed oil and its effect on engine performance and exhaust emissions, Applied Thermal Engineering. 29 (2009) 2265-2270

[4] K. Nantha Gopal, Karupparaj R. Thundil, Effect of pongamia biodiesel on emission and combustion characteristics of DI compression ignition engine, Ain Shanms Eng. J. (2014).

[5] Yang H, et al. Performance and emissions analysis of a diesel engine directly fuelled with waste cooking oil biodiesel. Int J Ambient Energy 2016;38(4):428-34.

[6] Suresh S, Sinha D, Murugavelh S. Biodiesel production from waste cotton seed oil: engine performance and emission characteristics. Biofuels 2016;7(6):689-98.

[7] Al-Hasan MI. Biodiesel production from waste frying oil and its application to a diesel engine. Transport 2013;28(3):276-89.
[8] Shaafi T, et al. Effect of dispersion of various nanoadditives on the performance and emission characteristics of a CI engine fuelled with diesel, biodiesel and blends. Renewable and Sustainable Energy Reviews, 49(2015)563-573.

[9] Vijay Kumar M, et al. The impacts on combustion, performance and emissions of biodiesel by using additives in direct injection diesel engine, Alexandria Engineering Journal (2018) 57, 509-516.

[10] G. Karavalakis, D. Hilari, L. Givalou, D. Karonis, S. Stournas, Storage stability and ageing effect of biodiesel blends treated with different antioxidants, Energy 36 (2011) 369-374.

[11] Selvan V A M, Anand R B, Udayakumar M. Effectsof cerium oxide nanoparticle addition in diesel and diesel-biodiesel-ethanol blends on the performance and emission characteristics of a CI engine.ARPNJEngApplSci2009;4:1-6.

[12] Basha

JS,AnandRB.AnexperimentalstudyinaCIengineusingn anoadditive blended water-diesel emulsionfuel.IntJGreenEnergy2011;8:332-48.

[13] FangsuwannarakK, TriratanasirichaiK.Improvementso fpalmbiodiesel properties byusingnano-TIO2 additive, exhaustemissionandengineperfor- mance. TheRomanianreviewprecisionmechanics.OptMechatr on 2013;43:111-8.

[14] Ors I,et al. The effects on performance, combustion and emission characteristics of DICI engine fuelled with $\mathrm{TiO} 2$ nanoparticles addition in diesel/biodiesel/nbutanol blends. Fuel 234 (2018) 177-188.

[15] Felipe Santos Dalólio, et al. Poultry litter as biomass energy: A review and future perspectives. Renewable and Sustainable Energy Reviews 76 (2017) 941-949

\section{AUTHORS PROFILE}

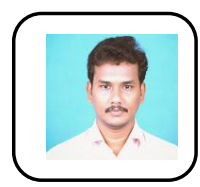

P.Karthikeyan, Assistant Professor, School of Mechanical Engineering, Sathyabama Institute of Science \& Technology, Chennai, India.

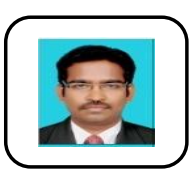

S.Yuvaraja, Assistant Professor, School of Mechanical Engineering, Sathyabama Institute of Science \& Technology, Chennai, India.

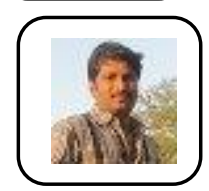

R.Kumarasubramanian, Assistant Professor, School of Mechanical Engineering, Sathyabama Institute of Science \& Technology, Chennai, India. 